\title{
Accelerometry Use to Study External Load in Combat Sports: An Example from Taekwondo
}

\author{
Fabrício B Del Vecchio ${ }^{1,2 *}$, Charles Bartel ${ }^{1,2}$, Leony M Galliano ${ }^{1,2}$ and David H Fukuda ${ }^{3}$ \\ ${ }^{1}$ Superior School of Physical Education, Federal University of Pelotas, Pelotas, Rio Grande do Sul, Brazil \\ ${ }^{2}$ Sports Training and Physical Performance Research Group \\ ${ }^{3}$ Institute of Exercise Physiology and Wellness, University of Central Florida, Orlando, Florida, USA
}

Submission: April 02, 2018; Published: April 13, 2018

*Corresponding author:Fabricio Boscolo Del Vecchio, Superior School of Physical Education, Federal University of Pelotas, Pelotas, Rio Grande do Sul, Brazil, Tel: +55 53 32732752; Email: fabricio_boscolo@uol.com.br

\begin{abstract}
The aim of this technical report is to present accelerometry data from a taekwondo (TKD) session. Eleven practitioners wore triaxial accelerometers during a typical TKD session in an attempt to evaluate external load. Direct observation of the training activities was also conducted. Information from each axis was recorded, and vector magnitude (VM) values were transformed to metabolic equivalents (MET). The average VM during the training session was $322.7 \pm 309.5$ au with an external load of $6.8 \pm 6.5 \mathrm{au} / \mathrm{min}$. There were statistically significant differences amongst the various training activities for each of the three axes (Y: $p<0.001 ; \mathrm{X}: \mathrm{p}<0.001 ; \mathrm{Z}: \mathrm{F}=\mathrm{p}<0.001$ ) and for the VM ( $\mathrm{p}<0.001$ ). The VM values during the greeting, pause, stretching, and upper limb exercises were lower than those observed in running, specific warm-up, lower limb exercises and combat simulation ( $\mathrm{p}<0.001$ for all). Exercise intensities varied during running (moderate: $71 \%$; vigorous: $29 \%$ ), the specific warm-up (light: 50\%; moderate: 25\%; vigorous: 25\%), and the combat simulation (light: 48\%; moderate: $52 \%$ ). General and specific warm-up, lower body technical training, and combat simulation showed intensity higher than upper limb technical training and stretching activities. Accelerometry seems to be a possible technology to measure external load in TKD.
\end{abstract}

Keywords: Martial arts; Sports; Accelerometry; Metabolic equivalent

Abbreviations: TKD: Taekwondo; MMA: Mixed Martial Arts; HR: Heart Rate; LAC: Blood Lactate Concentration; METs: Metabolic Equivalents; VM: Vector Magnitude

\section{Introduction}

Martial arts and combat sports are widely practiced by athletes and non-athletes for purposes related to the improvement of health [1] and physical fitness [2,3]. Striking modalities, such as taekwondo (TKD) [4] and boxing [5], grappling modalities, such as wrestling and judo [6], or a combination of the two, such as mixed martial arts (MMA) [7], exhibit high energy demands during training; however, methods of monitoring training intensities through quantification of internal or external load are limited [8].

Internal load during physical activity is reflective of the perceptions and feelings of the individual according to the motor tasks performed. In this context, the Borg scale (rated from 6 to 20) and the CR10 or OMNI scales are often used for the description of perceived effort. The product of these rating scales and the duration of a given training session, termed the "training load", have been used previously in combat sports. Physiological responses, including heart rate (HR) and blood lactate concentration ([LAC]) $[9,10]$, are also utilized in the evaluation of training intensities. Perceived effort seems to present low relationships with biological markers [10-12] and may be influenced by training history and the individual response of an athlete $[12,13]$. However, a delay in HR response occurs during successive high intensity intermittent bouts followed by rest periods [14], while [LAC], considered a marker of glycolytic activation, is increased during the initial efforts of a fight but may not indicative of the total work load [15].

Conversely, indicators of external load are primarily derived from time motion analysis variables $[16,17]$. Recently, Kirk et al. [15], proposed the use of accelerometry as a potential means of quantifying external load in mixed martial arts. However, it is not known if this type of equipment can be used in the measurement and differentiation of intensity in different combat sports activities. Thus, the objectives of this technical report are to present accelerometry data from a typical TKD training session and to examine the potential of this data to differentiate between activities of varying intensities. 


\section{Materials and Methodology}

\section{Participants}

The training session was completed by 11 TKD practitioners (7 male and 4 female athletes) with an average age of $17.3 \pm 7.63$ years old and median of 3.25 years of TKD training. Subjects or their legal guardians signed an informed consent (project was approved by local ethics committee, protocol 445.796/2013).

\section{Measures}

This is an exploratory study examining the use of accelerometers in the quantification of external load during a 45-minute typical TKD session. The session was separated into the following activities: initial greeting (1 min), running (2min), specific warm-up ( $3 \mathrm{~min}$ ), upper body technical training (7min), lower body technical training (technical skills, $5 \mathrm{~min}$, steps and displacement, $5 \mathrm{~min}$, and kicks on the strike shield, $3 \mathrm{~min}$ ), sparring (10min), stretching (5min) and final greeting (1min) and pauses ( $3 \mathrm{~min})$.

\section{Procedures}

Data collection was conducted with tri-axial (x: mediolateral; $\mathrm{y}$ : vertical; $\mathrm{z}$ : anteroposterior) accelerometers (wGT3X+; ActiGraph, LLC, Pensacola, FL) worn at the waist, on the medial line of the right side of the iliac crest, of the athletes throughout the previously outlined 45-minute TKD training session. Accelerometry data was collected as counts (arbitrary units: au) at a frequency of 30 Hertz over five-second epochs for each axis and 60-second epochs for calculation of metabolic equivalents (METs). Vector magnitude (VM; in au) was calculated from the

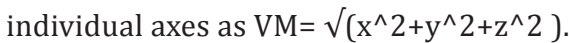

External load was quantified as the VM over the duration of activity (au/min). Physical activity efforts were classified using cut-off points proposed previously [18] as sedentary ( $\leq 100 \mathrm{au})$, low (>100 au), moderate ( $\geq 2200 \mathrm{au}$ ) and vigorous ( $\geq 4136 \mathrm{au})$ intensities. The time spent at each intensity (as a percentage of the total training time) during each training activity was also determined. METs were calculated from the equation: METs = $2.01+0.00171^{*}$ counts per $60 \mathrm{~s}[11]$

\section{Analysis}

Data are shown as mean \pm sd. One-way analysis of variance was used to compare values for each axis, VM, and METs across each of the observed training activities. When F-values were significant, post-hoc pair wise comparisons were conducted using Bonferroni adjustments. Pearson product moment correlations were used to examine the relationship between each axis and the calculated VM. The analyses were performed using Stata 12.0.

\section{Results}

The mean of VM during the 45-minute TKD training session was of $322.7 \pm 309.5 \mathrm{au}$ and an external load of $6.8 \pm 6.5 \mathrm{au} / \mathrm{min}$ was reached. Significant differences between activities were identified for the three axes (Y: $\mathrm{F}=183.9 ; \mathrm{p}<0.001 ; \mathrm{X}: \mathrm{F}=176.4$; $\mathrm{p}<0.001 ; \mathrm{Z}: \mathrm{F}=164.5 ; \mathrm{p}<0.001)$ and VM $(\mathrm{F}=189.4 ; \mathrm{p}<0.001)$ (Table 1). The VM values for greeting, pause, stretching and upper body technical training were lower than those observed for running, specific warm-up, lower body technical training and combat simulation ( $\mathrm{p}<0.001$ for all). The VM values for running were higher than those observed during the specific warm-up (p $=0.89$ ), while the $\mathrm{VM}$ values for the specific warm-up and combat simulation were similar to those observed during the lower body technical training ( $p=0.27$ and $p=0.44$, respectively). High correlations were found between the $\mathrm{X}, \mathrm{Y}$ and $\mathrm{Z}$ axis values and VM (Figure 1).
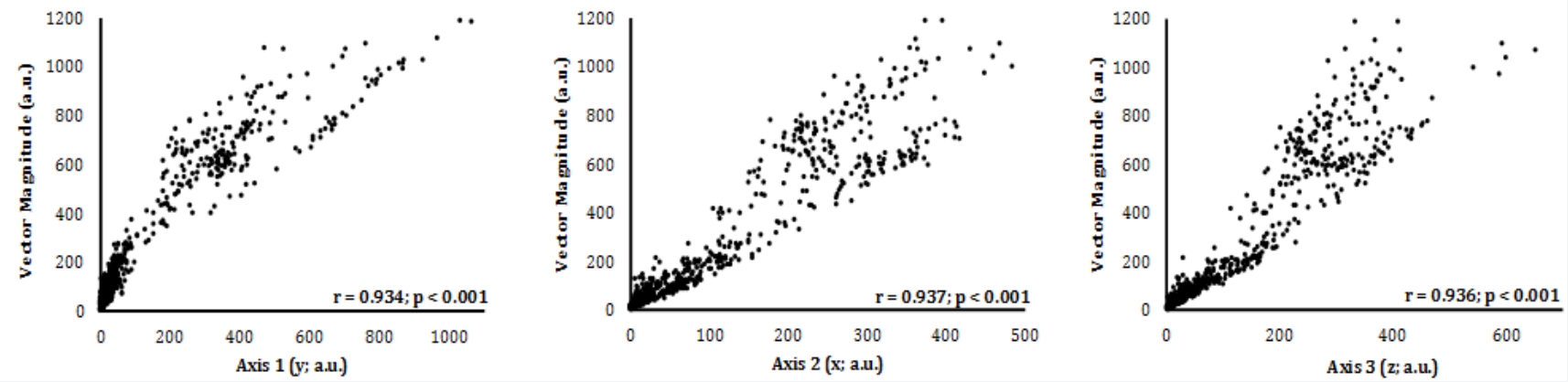

Figure 1: Relationships between vector magnitude and accelerometer data from the three axes (epoch $5 \mathrm{~s}$ ).

Table 1: Vector magnitude values for each segment of a taekwondo training session $(n=11)$.

\begin{tabular}{|c|c|c|c|c|}
\hline & \multicolumn{2}{|c|}{ Descriptive } & \multicolumn{2}{c|}{ 95\% CL } \\
\hline Activity & Mean & \pm SD & 14.58 & -31.17 \\
\hline Greetings & 22.87 & \pm 12.35 & 707.62 & -836.42 \\
\hline Running & 772.02 & \pm 13.15 & 560.67 & -864.31 \\
\hline Specific Warm-Up & 712.49 & \pm 342.41 & & UL \\
\hline
\end{tabular}


Journal of Physical Fitness, Medicine \& Treatment in Sports

\begin{tabular}{|c|c|c|c|c|}
\hline Upper Body Technical Training & 102.67 & \pm 73.89 & 90.95 & -114.4 \\
\hline Lower Body Technical Training & 600.32 & \pm 156.85 & 540.66 & -659.99 \\
\hline Combat Simulation & 530.44 & \pm 240.42 & 495.28 & -565.6 \\
\hline Stretching & 102.42 & \pm 61.09 & 85.58 & -119.26 \\
\hline Pauses & 40.94 & \pm 35.60 & 32.91 & -48.96 \\
\hline
\end{tabular}

SD: Standard Deviation; CL: Confidence Limits; LL and UL: Lower and Upper Limits

MET values, calculated from 60-s epochs, significantly different between the activities ( $F=34.95 ; p<0.001)$ (Figure 2). Running was classified as moderate (71\%) to vigorous (29\%) intensity exercise, while the specific warm-up consisted of light (50\%), moderate (25\%), and vigorous (25\%) intensities.
Stretching and upper body technical training was considered entirely light intensity exercise, whereas the lower body technical training was primarily moderate $(80 \%)$ intensity exercise. Sparring consisted of approximately equal time devoted to light $(48 \%)$ and moderate $(52 \%)$ intensity exercise.

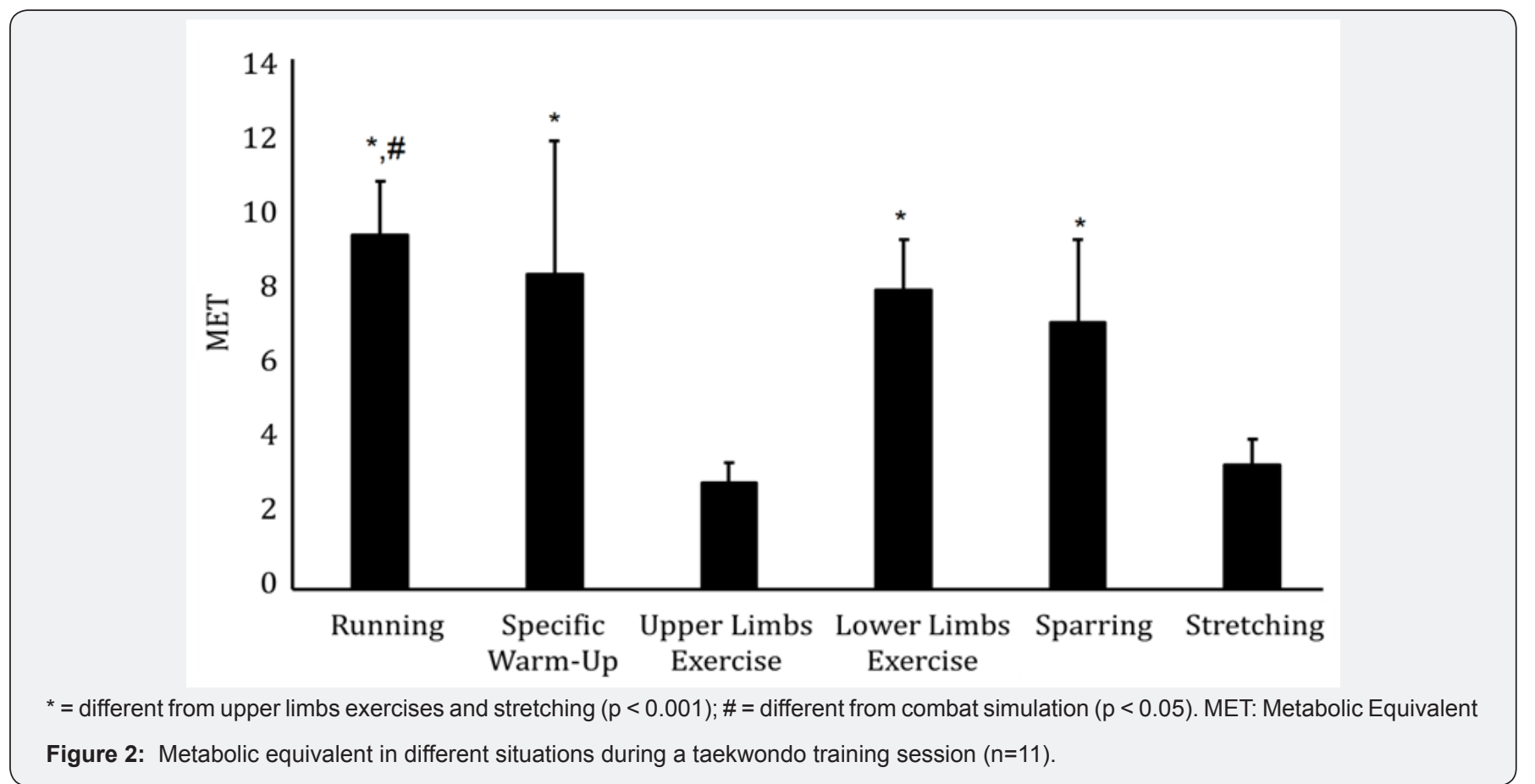

\section{Discussion}

This technical report is the first to examine the use of accelerometer data in the evaluation of exercise intensity during taekwondo-related training activities. Significant differences were shown between activities for individual axes $(\mathrm{X}, \mathrm{Y}, \mathrm{Z})$ and VM with the highest values reported for running and the lowest for upper body technical training and stretching. These findings provide support for future investigation of the use of accelerometers during striking combat sports training.

A single 15-minute MMA bout has been reported to result in an accumulated player load, a variant of VM, of $224.32 \pm$ 26.59 au measured using a triaxial accelerometer (Minimax $\mathrm{X} 3$, Catapult Innovations, Australia) with a sampling rate of $100 \mathrm{~Hz}$. A high correlation coefficient ( $r=0.980$ ) was found between lactate concentrations and accumulated player load during the simulated MMA bout, which provides evidence for the relationship between accelerometry data and physiological response [15]. The accumulated player load per minute during the MMA bout was greater than the VM per unit of time in the current investigation $(14.91 \pm 1.78 \mathrm{au} \bullet \mathrm{min}-1$ versus $6.8 \pm 6.5$ au $\bullet$ min-1) as would be expected when considering differences in the sporting environment as well as between training activities and simulated competition.

Data from running-based team sports has demonstrated external load estimates similar to a MMA bout with soccer players having an accumulated player load per minute of 13.15 au•min-1 during a 90-minute training session [19], Australian football players having a value of 15.65 au $\bullet$ min- 1 during a match [20]. Accelerometer-derived player load has also shown to discriminate between midfielders and other positions during professional soccer match play [21]. The potential ability to distinguish between athletes tasked with differing roles combined with the current findings, namely differences in VM between non-contact activities (e.g. specific warm-up and upper 
body technical training) during a TKD training session, suggests the need for more thorough investigation.

Methodological consideration should also be given to the accelerometer during physical exercise, as the placement and processing criteria, but there is no consensus about these issues [22]. The researches need take care about these aspects, because they have an important role in the outcomes. The accelerometers in the current study were placed on the hips of the participants which may have played a role in the differences between upper and lower body measurements.

New studies examining common internal/external load control methods and accelerometry data in taekwondo should be conducted in order to evaluate the relationship amongst these approaches. Specific consideration may be given to the ability of accelerometer-derived measures to differentiate between the loads associated with contact and non-contact activities. With additional investigation, accelerometry may prove to be a useful alternative for load control in combat sports.

\section{Conclusion}

In conclusion, was verify that general and specific warmup, lower body technical training, and combat simulation showed intensity higher than upper limb technical training and stretching activities. Also, we consider that the accelerometry can be a method of monitoring training intensities in comba

\section{References}

1. Woodward TW (2009) A rewiew of the effects of martial arts practice on health. WMJ 108(1): 40-43.

2. Douris P, Chinan A, Gomez M, Aw A, Steffens D (2004) Fitness levels of middle aged martial art practitioners. Br J Sports Med 38(2):143-147.

3. Farzad B, Gharakhanlou R, Agha Alinejad H, Curby DG, Bayati M (2011) Physiological and performance changes from the addition of a sprint interval program to wrestling training. J Strength Cond Res 25(9): 2392-2399.

4. Bridge CA, Santos JFS, Chaabène H, Pieter W, Franchini E (2014) Physical and physiological profiles of taekwondo athletes. Sports Med 44(6): 713-733.

5. Chaabène $H$, Tabben $M$, Mkaoue B, Franchini E, Negra Y (2015) Amateur boxing physical and physiological attributes. Sports Med 45(3): 337-352.

6. Franchini E, Del Vecchio FB, Matsushigue KA, Artioli GG (2011) Physiological profiles of elite judo athletes. Sports Med 41(2): 147-166.

7. Del Vecchio FB, Hirata SM, Franchin E (2011) A review of time-motion analysis and combat development in mixed martial arts matches at regional level tournaments. Percept Mot Skills 112(2): 639-648.
8. Padulo J, Chaabène H, Tabben M, Haddad M, Gevat C (2014) The construct validity of session RPE during an intensive camp in young male Karate athletes. Muscles Ligaments Tendons J 4(2): 121-126.

9. Bridge CA, Jones MA, Drust B (2009) Physiological responses and perceived exertion during international Taekwondo competition. Int J Sports Physiol Perform 4(4): 485-93.

10. Branco BH, Massuça LM, Andreato LV, Marinho BF, Miarka B (2013) Association between the rating perceived exertion heart rate and blood lactate in successive Judo fights (Randori). Asian J Sports Med 4(2): 125-130.

11. Serrano MA, Salvador A, González Bono EG, Sanchís C, Suay F (2001) Relationships between recall of perceived exertion and blood lactate concentration in a judo competition. Percept Mot Skills 92(3): 11391148.

12. Haddad M, Chaouachi A, Castagna C Wong del P, Behm DG (2011) The construct validity of session RPE during an intensive camp in young male Taekwondo athletes. Int J Sports Physiol Perform 6(2): 252-263.

13. Franchini E, Del Vecchio FB (2012) Subjective perceived exertion in the judo athlete's session seven weights and one measure. Rev Bras Med Esporte 18(2): 134-138.

14. Green JM, McLester JR, Crews TR, Wickwire PJ, Pritchett RC (2006) RPE association with lactate and heart rate during high-intensity interval cycling. Med Sci Sports Exerc 38(1): 167-172.

15. Kirk C, Hurst HT, Atkins S (2015) Measuring the Workload of Mixed Martial Arts using Accelerometry Time Motion Analysis and Lactate. Int J Perform Anal Sport 15(1): 359-370.

16. Matsushigue KA, Hartmann K, Franchini E (2009) Taekwondo Physiological responses and match analysis. J Strength Cond Res 23(4): 1112-1117.

17. Andreato LV, Julio UF, Panissa VLG, Esteves JVC, Hardt F (2015) Brazilian jiu-jitsu simulated competition Part II Physical performance time-motion technical-tactical analyses and perceptual responses. J Strength Cond Res 29(7): 2015-2025.

18. Freedson PS, Pober D, Janz KF (2005) Calibration of accelerometer output for children. Med Sci Sports Exerc 37(11): 523-530.

19. Casamichana D, Castellano J, Calleja Gonzalez J, Roman J, Castagna C (2013) Relationship between indicators of training load in soccer players. J Strength Cond Res 27(2): 369-374.

20. Mooney M, Cormack S, O Brien B Coutts AJ (2013) Do physical capacity and interchange rest periods influence match exercise-intensity profile in australian football. Int J Sports Physiol Perform 8(2): 165-172.

21. Dalen T, Ingebrigtsen J, Ettema G, Hjelde GH, Wisloff U (2015) Player load acceleration and deceleration during 45 competitive matches of elite soccer. J Strength Cond Res 30(2): 351-359.

22. Quante M, Kaplan ER, Rueschman M, Cailler, M Buxton OM (2015) Practional considerations in using accelerometers to assess physical activity sedentary behavior and sleep. Sleep Health 1(4): 275-284. 
(C) This work is licensed under Creative

(C) Commons Attribution 4.0 License

DOI: 10.19080/JPFMTS.2018.03.555608

\section{Your next submission with Juniper Publishers} will reach you the below assets

- Quality Editorial service

- Swift Peer Review

- Reprints availability

- E-prints Service

- Manuscript Podcast for convenient understanding

- Global attainment for your research

- Manuscript accessibility in different formats

( Pdf, E-pub, Full Text, Audio)

- Unceasing customer service

Track the below URL for one-step submission https://juniperpublishers.com/online-submission.php 